\title{
Asset Management and Method of Power Grid Projects based on the Life Cycle Theory
}

\author{
Jiang Zhu ${ }^{1, a^{*}}$, Hang Yin ${ }^{2, b}$, Chaochen $X^{3, c}$, Yang Wei ${ }^{4, d}$ and Guanqing Wang ${ }^{5, e}$ \\ ${ }^{1}$ School of Economics and Management, North China Electric Power University, Beijing 102206, \\ China \\ ${ }^{2}$ Heibei Electric Power Engineering Supervision Company Limited, Shijiazhuang 050021, China \\ ${ }^{3}$ State Grid Fujian Economic Research Institute, Fuzhou 350012, China \\ ${ }^{4}$ State Grid Sichuan Electric Power Research Institute, Chengdu 610072, China \\ ${ }^{5}$ State Grid East Inner Mongolia Electric Power Company Limited, Hohhot 010020, China \\ azhujiang1125@126.com, b49248722@qq.com, cxcchen520@sina.com, d81087478@qq.com, \\ ewangguaner123@126.com
}

Keywords: power grid project; asset management; cost calculation model; life cycle theory Abstract. With the large scale development of the power grid, the refined asset management has become very important in the power grid enterprises. The traditional asset management mode is extensive which can not meet the requirements and needs from the power grid enterprises. In this paper, an improved management organization system will be constructed on the purpose of spreading the concept of life cycle asset management of power grid projects. In addition, a cost calculation model is given to help the power grid enterprises to control and monitor the power grid project costs. The considerations in this model, such as initial investment, operation cost, reliability cost and environmental protection cost, will provide references for refined asset management of power grid projects.

\section{Introduction}

With the rapid speed of power grid construction and investment, the assets of the power grids have formed a large scale in China. However, the asset quality and efficiency of power grid are still low which seriously hampered the healthy and development of the power grid enterprises. To the power grid enterprises, it's necessary to manage the power grid projects carefully.

Under the traditional management mode, the investment, construction and operation were decentralized. That makes the management departments can not communicate with each other effectively enough. Facing with the new developing problems in power grid engineering, the Life Cycle Cost theory (LCC) can deal with the problem from a macro perspective.

In the LCC management mode, the power grid enterprise should adjust and improve its organization firstly and form an integrated one instead. In this new organization, the process of investment, construction and operation will be controlled totally. Meanwhile, the clear divisions of the functions ensure the effective information communication. Consequently, the manager can make specific decisions to power grid design and construction from its life cycle.

So based on LCC theory, a new management mode will be built in this paper. It will consider with all the stages of power grid project. From the power grid enterprise's angle, the asset calculation model will be studied based on the power grid equipment cost. The uncertainty research of power grid cost will provide a basis for further LCC management of power grid project. It can also help the power grid enterprise to build an asset management system and lead a sustainable developing way for power grid enterprise. 


\section{Literature Reviews}

The LCC asset management researches were mainly from two aspects: equipment management and planning applications. There are some research results in these aspects.

(1) Equipment management. With the fuzzy modeling methods, reliability analysis was introduced to solve the prediction and decision-making problems of the transformer [1]. The retired and update strategies were deeply studied based on LCC. As well, the update and maintain strategies of equipments were explored by probability distribution method [2]. Markov Chain Model was also used in the cost analysis of transformer substation and its application was proved well in the equipment aging stage [3]. Under the circumstances of electric system reform, a 3R method (Run, Refurbish and Replacement) was proposed to control the equipment risks of the power grid project [4]. Based on the $3 \mathrm{R}$ method, the equipment investment and equipment risks will be balanced to enhance and improve the asset management levels.

(2) Planning applications. In the process of planning and design of power grid engineering, LCC management mode is conducive to control the asset risks. By considering with the power distribution network design, LCC was adopted to improve the voltage level design [5]. With Matlab software, a life cycle cost management model about mixed energy was constructed in order to decide the optimal combination energy consumption plan and reduce the cost [6]. By taken LCC analysis method, the configuration problem of different resonant circuits and theirs breakers was studied. The result showed that providing a degree of elasticity can design a lowest cost circuit [7]. Based on life cycle cost, an economic assessment was given to analyze the economic feasibility of a power plant. The results provided a new path or method for plant investment decision [8].

With the analysis above, LCC theory was popularly used in electric power engineering management. It is imperative to bring it into the asset management of power grid project and explore its cost model in the life cycles. The improved organization based on LCC theory and the cost calculation model will be introduced as follows.

\section{Improved Management Organization of Power Grid Projects}

As mentioned before, an improved management organization should be the first step for asset LCC management. Combing with the practices of power grid projects in China, an improved asset management organization is built as shown in Fig.1.

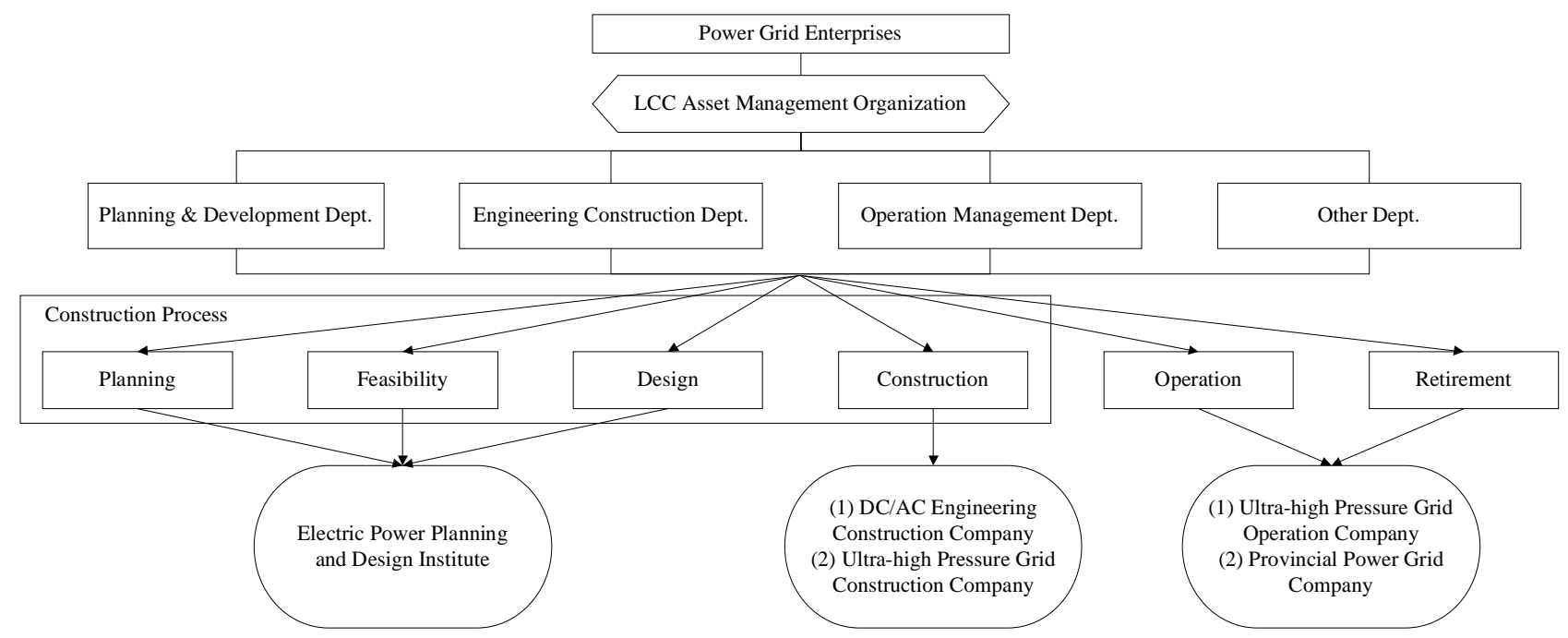

Fig.1 An improved asset management organization of power grid projects

As shown in Fig.1, as a total life cycle management method, the mind and idea should be present in every stage of power grid project, such as planning, design, construction and operation. In other words, 
each process should take the asset into the consideration. The improved organization system has the two new features:

(1) Integration. The traditional power grid management focused on the construction process. Each stage and department only cared about the businesses belongs to themselves. However, under the improved organization system, the total life cycle cost should be considered at the beginning of the power grid projects. The whole construction process will be controlled and supervised in this system. Meanwhile, all processes and theirs information will be integrated and shared to every department. The collected information is the basis of the power grid project and asset management which will provide references for decision makers in order to fulfill the asset optimization.

(2) Coordination. The coordination in the improved organization system means that the talent resource communication and information integration are important. In the different process of power grid construction, the work targets of all staff should be unified and serve for the asset optimization of power grid projects. Information exchange system, benefit sharing system and incentive system should be formulated in the organization to ensure the spread of this management concept.

Based on this improved organization system, a cost calculation model will be built in next section with the purpose of cost optimization of power grid project in total life cycle.

\section{Cost Calculation Model of Power Grid Projects}

Under the improved asset management system, all processes of power grid project should be taken into account and optimized. Compared with traditional management mode, the improved cost calculation model will mainly consider the cost of reliability and environmental protection.

(1) Reliability cost

The cost ensuring the power supply reliability is called reliability cost. In other words, it is not just a simple cost which can be seen as a service quality from supplier to consumers. In short term, the reliability will be guaranteed by auxiliary service, such as frequency modulation, voltage regulation and backup. In long term, it should be protected by enough capacity.

The power outage is a direct form of reliability cost. The reducing losses by power outage can be taken as a benefit of reliability investment. The optimal capacity should be the minimum capacity ensuring the power grid reliability. In this paper, the reliability cost will be calculated by reliability price.

(2) Environmental protection cost

Unlike the power plants, the power grids do not produce direct pollutions. The main environmental protection costs are from electromagnetic radiation and noise pollution. They are harmful to human beings, so there are strict control standards in the process of power grid operation. The environmental assessment, environmental monitoring and penalty constitute the environmental protection costs. Different design and planning will produce different costs. A ratio of initial investment will be used in this model to present this cost.

A cost calculation model is built with the considerations of initial investment, operation cost, reliability cost and environmental protection cost.

or

$$
\begin{gathered}
\min P V=P+\sum_{t=1}^{T} \frac{C O_{t}+C R_{t}+C E_{t}}{(1+r)^{t}}+\frac{S_{T}}{(1+r)^{T}} \\
\min A V=\frac{r(1+r)^{T}}{(1+r)^{T}-1} \times\left[P+\sum_{t=1}^{T} \frac{C O_{t}+C R_{t}+C E_{t}}{(1+r)^{t}}+\frac{S_{T}}{(1+r)^{T}}\right]
\end{gathered}
$$

$P V$ stands for the present value of the power grid project in equation (1) and $A V$ stands for annual value in equation (2). $P$ represents the initial investment of power grid project. The discount rate is $r . T$ is the total life cycle of power grid project, and $t$ stands for the $t$ th year of the life cycle $T$. $C O_{t}$ stands for the operation cost in the $t$ th year, it is decided by design plans and different chosen equipments. $C R_{t}$ stands for the reliability cost, it can be similarly calculated by reliability price. $C E_{t}$ represents the 
environmental protection cost, it can be got via $B_{t} \times P$ where $B_{t}$ stands for the ratio of environmental protection cost in the $t$ th year. And ST stands for the salvage of the power grid project.

The model can be used to make decisions and choices between different power grid power plans. Based on the life cycle theory, it can cover the shortage of traditional management method, especially in the aspects of long term benefits, reliability and economy. The result can accord well with practice even more.

\section{Summary}

In conclusion, the asset management is one of the most important contents in power grid projects. A suitable system or method can enhance the management level of it and help the managers to control the cost risks well. In this paper, by introducing the theory of total life cycle, an improved asset management organization was built firstly. All construction processes of power grid project are taken into the consideration, such as planning design, construction, and operation. It will help the enterprises to integrate the resources and improve the information communication. Then a cost calculation model was given to analyze the factors influential to the power grid costs. The model gave full considerations to the cost of reliability and environmental protection. Compared to traditional asset calculation, the effectiveness proposed in this paper is positive and it will be widely used in practice.

\section{References}

[1] Arshad M. A novel fuzzy logic technique for power transformer asset management. In: Islam S.M, eds. Industry Applications Conference, 4lst IAS Annual Meeting, 2006, pp: 276-286.

[2] Anders G.J. A probabilistic approach to life cycle management. In: Endrenyi J, eds. Power Tech, 2005 IEEE Russia, 2005, 1-6.

[3] Politano D, Frohlich K. Calculation of stress-dependent life cycle costs of a substation subsystemdemonstrated for controlled energization of unloaded power transformers. IEEE Transactions on Power Delivery, 2006, 21(4): 2032-2038.

[4] Ray Mohapatra SK, Subrata Mukhopadhyay. Risk and asset management of transmission system in a reformed power sector. In: Power India Conference, 2006 IEEE, 2006, pp: 725-730.

[5] Curcic S, Strbac G, Zhang XP. Effect of losses in design of distribution circuits. Generation, Transrnission and Distribution, 2011, 148(4): 343-349.

[6] Negrea I, Dragusin G. Energy Management in a Hybrid Energy System using the Simulation Program Matlab and the LCC (Life Cycle Cost) Method. In: Mogan P, eds. Soft Computing Applications, 2007, pp: 217-220.

[7] Meyer C, De Doncker RW. LCC analysis of different resonant circuits and solid-state circuit breakers for medium-voltage grids. IEEE Transactions on Power Delivery, 2006, 21(3): 1414-1420.

[8] Rodriguez, O'Neill-Carrillo E. Economic assessment of distributed generation using life cycle costs and environmental externalities. In: Endren J, eds. Power Symposium, 2005. Proceedings of the 37th Annual North American, 2005, pp: 412-420. 